\title{
ALTERAÇÕES NOS ATRIBUTOS FÍSICOS DE UM LATOSSOLO VERMELHO SOB PLANTIO DIRETO INDUZIDAS POR DIFERENTES TIPOS DE ESCARIFICADORES E O RENDIMENTO DA SOJA ${ }^{(1)}$
}

\author{
Vitor Cauduro Girardello( ${ }^{(2)}$, Telmo Jorge Carneiro Amado(3), \\ Rodrigo da Silveira Nicoloso ${ }^{(4)}$, Tiago de Andrade Neves Hörbe ${ }^{(5)}$, \\ Ademir de Oliveira Ferreira ${ }^{(6)}$, Fabiano Mauricio Tabaldi ${ }^{(7)} \&$ \\ Mastrângello Enívar Lanzanova ${ }^{(8)}$
}

\begin{abstract}
RESUMO
A compactação do solo, quando em níveis elevados, é um processo de difícil reversão sob sistema de plantio direto (SPD), especialmente em solos argilosos. Geralmente, a sua ocorrência em áreas comerciais de grãos é descontínua e restrita a áreas com histórico de pressões associadas ao trânsito intenso de máquinas agrícolas. $\mathrm{O}$ objetivo deste trabalho foi investigar as alterações nos atributos físicos de um Latossolo Vermelho distrófico de textura argilosa (450 $\left.\mathrm{g} \mathrm{kg}^{-1}\right)$ promovidas por dois tipos de escarificações sítio-específico e uma convencional (aleatória), bem como seus efeitos sobre o rendimento da soja. Para isso, selecionou-se no município de Victor Graeff, na região do planalto do RS, uma lavoura de 50,6 ha manejada sob SPD por longo prazo e, recentemente, com agricultura de precisão. O clima local é subtropical Cfa, com precipitação pluvial anual oscilando entre 1.500 e $1.750 \mathrm{~mm}$, temperatura média de $20^{\circ} \mathrm{C}$ e altitude de $490 \mathrm{~m}$. Com base nos mapas de rendimento de três safras anteriores, a área foi subdividida em três zonas de potencial produtivo. Na zona de baixo rendimento (ZB) foram implantados os seguintes tratamentos: (a) escarificação convencional com profundidade
\end{abstract}

\footnotetext{
(1) Parte da Dissertação de Mestrado do primeiro autor apresentada no Programa de Pós Graduação em Ciência do Solo, Universidade Federal de Santa Maria - UFSM. Recebido para publicação em 23 de fevereiro de 2011 e aprovado em 2 de setembro de 2011.

(2) Doutorando em Engenharia Agrícola, Universidade Federal de Santa Maria - UFSM. Av. Roraima 1000, CEP $97105-900$ Santa Maria (RS). Bolsista CAPES. E-mail: vitorgirardello@gmail.com

(3) Professor Associado no Departamento de Solos, UFSM. Bolsista CNPq. E-mail: tamado@smail.ufsm.br

(4) Pesquisador A na Embrapa Suínos e Aves. Rod. BR 153, Km 110, Caixa Postal 21, CEP 89700-000 Concórdia (SC). E-mail: rodrigo.nicoloso@cnpsa.embrapa.br

(5) Mestrando em Ciência do Solo, UFSM. Bolsista CAPES. E-mail: tiagohorbe@hotmail.com

(6) Doutorando em Ciência do Solo, UFSM. Bolsista CNPq. E-mail: aoferreira1@yahoo.com.br

(7) Engenheiro-Agrônomo, Departamento de Tecnologia, STARA S/A Indústria de Implementos Agrícola, CEP $99470-000$ Não Me Toque (RS). Email: fabianotabaldi@yahoo.com.br

${ }^{(8)}$ Professor Assistente da Universidade Estadual do Rio Grande do Sul - UERGS. Rua Cipriano Barata 47, CEP $98600-000$ Três Passos (RS). E-mail: mastrangello-lanzanova@uergs.edu.br
} 
fixa de 0,30 m (EC); (b) escarificação sítio-específico com equipamento Fox® ${ }^{\circledR}$ com profundidade fixa de 0,30 m (ESEF); (c) escarificação sítio-específico com equipamento Fox ${ }^{\circledR}$ com profundidade de atuação variável $(0,10$ a $0,30 \mathrm{~m})$, em função da resistência máxima do solo à penetração (ESEV); e (d) controle sem escarificação (SE). A zona de alto rendimento (ZA) foi usada como referência para avaliar o efeito dos tratamentos no rendimento de grãos. Os tratamentos foram implantados em faixas paralelas de $100 \times 20 \mathrm{~m}$, seguindo o delineamento de blocos casualizados. Avaliaram-se, em três épocas, a densidade do solo, macroporosidade, microporosidade e porosidade total nas profundidades de $0,0-0,05,0,05-0,10,0,10$ 0,15 e $0,15-0,20 \mathrm{~m}$, bem como a infiltração de água no solo. Os resultados da caracterização inicial dos atributos do solo por zona de rendimento evidenciaram maior densidade do solo e menor porosidade total, na profundidade de $0,15-0,20 \mathrm{~m}$, na ZB em relação à ZA. Em todos os tratamentos com escarificação mecânica, observouse, logo após o preparo, incremento da infiltração de água em relação ao SE, que aumentou em torno de quatro vezes nos tratamentos EC e ESEV em comparação a esse controle. No entanto, o efeito da escarificação, independentemente do tipo de escarificador, foi efêmero; transcorridos sete meses, verificou-se decréscimo na infiltração de água no solo, que não diferiu do tratamento controle. Entre os escarificadores investigados, o ESEV destacou-se pela manutenção da cobertura do solo em relação ao EC e proporcionou maior rendimento de soja. Contudo, sob condições de elevada precipitação pluvial não foi observado incremento no rendimento da soja nos tratamentos com escarificação mecânica, em relação ao tratamento controle (SE).

Termos de indexação: agricultura de precisão, escarificação sítio-específico, compactação do solo, infiltração de água no solo.

\section{SUMMARY: CHANGES IN PHYSICAL PROPERTIES OF A RED OXISOL AND OF SOYBEAN YIELD UNDER NO-TILLAGE AFFECTED BY CHISEL PLOW TYPES}

Soil compaction at high intensity degrees is a hardly reversible process in the no-till system (NT), mainly in clayey soils. Generally, its occurrence in croplands is often irregular and restricted to areas with a previous history of pressures associated to intensive traffic of agricultural machineries. The purpose of this study was to investigate changes in soil physical properties of a red Oxisol with clayey texture $\left(450 \mathrm{~g} \mathrm{~kg}^{-1}\right)$ and soybean yield, caused by two sitespecific chisels and conventional (random) chisel tillage. For this work, a 50.6 ha cropland area under long-term no-till and site-specific farming was selected in the Municipality of Victor Graeff, located in the plateau region of Rio Grande do Sul. The climate is a subtropical Cfa with annual rainfall ranging from 1500 to $1750 \mathrm{~mm}$, average temperature of $20{ }^{\circ} \mathrm{C}$, at $490 \mathrm{~m}$ asl. Based on three crop yield maps, the field was subdivided in three management zones with distinct yield potential where the soil physical properties were investigated. The following treatments were established in the low yield zone (LZ): (a) conventional chiseling at fixed soil depth $(0.30 \mathrm{~m})(\mathrm{CC})$; (b) site-specific chiseling with Fox ${ }^{\circledR}$ equipment at fixed soil depth $(0.30 \mathrm{~m})(\mathrm{SSCF}) ;(\mathrm{c})$ site-specific chiseling with Fox ${ }^{\circledR}$ equipment at variable soil depth $(0.10$ to $0.30 \mathrm{~m})$ based on maximum soil penetration resistance maps (SSCV); and (d) control without chiseling $(C W C)$. The high yield zone $(H Z)$ was used as a reference to evaluate treatment effects on soybean grain yield. Treatments were arranged in parallel strips of $100 \times 20 \mathrm{~m}$, in a randomized block design. In three evaluations, the soil water infiltration and bulk density, macro and microporosity and total porosity were evaluated in the layers $0.0-0.05,0.05-0.10$, $0.10-0.15$ and $0.15-0.20 \mathrm{~m}$. The results of the initial soil characterization showed higher bulk density and lower soil porosity in the 0.15-0.20 m layer, in the LZ in relation to HZ. Treatments showed an immediate increase of water infiltration after chiseling. The increase in water infiltration in treatments CC and SSCV was four times the water infiltration observed in the CWC. However, the chiseling effect, regardless of the chisel type, was ephemeral and after seven months there was a decrease of water infiltration in chiseled soil, similar to CWC. Of the chisel types, the SSCV was superior to CC by maintaining higher soil coverage and by increasing soybean yield. Although, in a crop season with high rainfall, no positive effects of chiseling on soybean yield were noticed, in relation to CWC.

Index terms: precision farming, site-specific chiseling, soil compaction, water infiltration. 


\section{INTRODUÇÃO}

Atualmente, o sistema plantio direto (SPD), no Brasil, abrange aproximadamente 25 milhões de hectares. Em solos de textura argilosa, esse sistema, quando manejado em monocultivo de soja e baixa adição de resíduos vegetais na entressafra, geralmente apresenta compactação do solo (Camara \& Klein, 2005; Silva et al., 2009).

A compactação é um processo antrópico resultante da compressão induzida pela pressão de implementos agrícolas e de animais, que resulta na alteração da estrutura, com redução do volume de ar do solo e aumento da densidade aparente (Dias Júnior, 2000; Silva et al., 2010). Com isso, a função de partição de água pelo solo é alterada, resultando em redução da infiltração e incremento da enxurrada. Assim, a determinação da infiltração em agroecossistemas torna-se relevante, pois existe uma relação inversa desta com a erosão (Roth et al., 1985; Pott \& De Maria, 2003). Em casos em que a compactação é severa, a produtividade das culturas pode ser alterada, especialmente em sistemas com mínima mobilização do solo (Nicoloso et al., 2008; Amado et al., 2009).

Dos atributos físicos do solo utilizados para avaliar o grau de compactação, destacam-se: densidade do solo, resistência à penetração, macroporosidade, infiltração de água e, mais recentemente, a pressão de préconsolidação (Pacheco \& Cantalice, 2011). Os valores de densidade crítica são variáveis em função das características do solo (Tormena et al., 1998; Lima et al., 2003). Reichert et al. (2009) reportaram uma relação linear inversa entre a densidade crítica e o teor de argila. Assim, especificamente para Latossolos, os valores de densidade crítica podem variar de $1,21 \mathrm{Mg} \mathrm{m}^{-3}$ para um teor de argila de $750 \mathrm{~g} \mathrm{~kg}^{-1}$ (De Maria et al., 1999) a $1,68 \mathrm{Mg} \mathrm{m}^{-3}$ para um teor de $271 \mathrm{~g} \mathrm{~kg}^{-1}$ (Beutler \& Centurion, 2004).

A macroporosidade é outro importante indicador do estado de compactação, visto que a porosidade regula várias propriedades ecológicas do solo (Reichert et al., 2009). Valores de macroporosidade entre $0,05 \mathrm{e}$ $0,10 \mathrm{~m}^{3} \mathrm{~m}^{-3}$ têm sido reportados como restritivos ao rendimento das culturas (Tormena et al., 1998; Beutler \& Centurion, 2004). Contudo, restrições ao desenvolvimento radicular, previstas com base em atributos físicos, nem sempre se refletem em redução no rendimento, uma vez que as culturas apresentam diferente tolerância à compactação (Reichert et al., 2009) e existe uma complexa interação com as condições climáticas e edáficas.

A infiltração de água é um dos processos que melhor refletem as condições físico-hídricas do solo, pois a qualidade estrutural condiciona uma distribuição do tamanho de poros favorável ao crescimento de raízes, à aeração e à infiltração de água no solo (Pott \& De Maria, 2003).

A ocorrência de déficits hídricos de curta duração, durante a safra de verão, tem sido recorrente no RS.
De 1987 a 2004, observou-se que sete eventos de estiagens ocasionaram, apenas nas culturas da soja e do milho, perdas na produção de 23,6 milhões de toneladas. Esse fato tem conduzido à busca de alternativas visando ao armazenamento de água no solo e à redução da suscetibilidade dos sistemas agrícolas à estiagem. A escarificação mecânica do solo favorece o desenvolvimento radicular das plantas, incrementa a rugosidade superficial, eleva a taxa de infiltração e a capacidade de armazenamento de água no solo, resultando em maior disponibilidade de água às culturas (Secco \& Reinert, 1997; Abreu et al., 2004; Camara \& Klein, 2005). No entanto, em estudos conduzidos sob solo argiloso, Nicoloso et al. (2008) reportaram que a escarificação apresentou efeito de curta duração na melhoria dos atributos físicos, não ultrapassando o período de uma safra agrícola. Araujo et al. (2004) sustentaram que a escarificação utilizada de forma isolada, em áreas sob SPD, não mostrou resultados positivos no rendimento de culturas de grãos.

A escarificação mecânica é uma operação de elevada demanda de potência, alto consumo de combustível e de tempo; portanto, preferencialmente, deveria ser aplicada somente onde a compactação é severa. Nesse contexto, a escarificação sítio-específico destaca-se como alternativa à escarificação aleatória, diminuindo a mobilização do solo no SPD.

O objetivo deste trabalho foi avaliar a eficiência das escarificações sítio-específico e a convencional (aleatória), quanto à melhoria dos atributos físicos, à manutenção da cobertura do solo e ao incremento do rendimento de soja, em um Latossolo Vermelho do Planalto do RS manejado sob SPD contínuo por 15 anos, que apresentava indícios de moderada compactação do solo.

\section{MATERIAL E MÉTODOS}

Para a realização deste estudo foi escolhida uma área agrícola que apresentava indícios aparentes de compactação do solo, pertencente a um associado da Cooperativa Agropecuária e Industrial (COTRIJAL), no município de Victor Graeff, sob coordenadas geográficas de $28^{\circ} 31^{\prime} 40^{\prime \prime} \mathrm{S}$ e $52^{\circ} 40^{\prime} 18^{\prime \prime} \mathrm{W}$. O solo do local é classificado como Latossolo Vermelho distrófico (Embrapa, 2006), com relevo suavemente ondulado e textura argilosa (450 $\left.\mathrm{g} \mathrm{kg}^{-1}\right)$. No quadro 1 é apresentada a análise química do solo realizada quando da implantação do experimento. O clima da região, segundo a classificação de Köppen, é do tipo Cfa subtropical (Nimer, 1989). A temperatura média normal do mês mais quente ocorre em janeiro $\left(24,6^{\circ} \mathrm{C}\right)$, e a do mês mais frio, em junho $\left(12,9^{\circ} \mathrm{C}\right)$. As chuvas são distribuídas regularmente em todos os meses do ano, com precipitação pluvial anual oscilando entre 1.500 e $1.750 \mathrm{~mm}$.

$\mathrm{Na}$ condução do experimento, as precipitações pluviais foram regularmente distribuídas durante o 
ciclo da cultura da soja, com déficits hídricos de curta duração (Figura 1). As precipitações pluviais totalizaram $560 \mathrm{~mm}$ até o final do ciclo da cultura e ocorreram em volume satisfatório nas fases críticas da soja, com valor médio de $4 \mathrm{~mm} \mathrm{dia}{ }^{-1}$, quantidade suficiente para atender à demanda de evapotranspiração na maioria dos estádios fenológicos; nenhum evento de precipitação pluvial ultrapassou os $40 \mathrm{~mm} \mathrm{dia}{ }^{-1}$, fato que favoreceu a infiltração de água no solo.

A área selecionada possui 50,6 ha e está sendo manejada sob SPD há aproximadamente 15 anos, tendo como principais culturas comerciais, durante a safra de verão, a soja (Glycine max L. Merr.) e o milho (Zea mays L.). Nos cultivos de inverno, o trigo (Triticum aestivum L.) é a principal cultura comercial; a aveia-preta (Avena strigosa L.) é utilizada como cultura de cobertura. A partir de 2005, a área passou a ser integrante do Projeto Aquarius de agricultura de precisão (www.ufsm.br/projetoaquarius), passando a ser manejada com técnicas de agricultura de precisão, sendo corrigida quimicamente com aplicações em taxa variada de fertilizantes e gerados mapas de rendimento com uma colhedora MF32 equipada com o sistema Fieldstar. Essa máquina possuía pneus dianteiros com as especificações 18.4-34RI e pneus traseiros tipo 14.9-24RI, com pressão de insuflação de 20 psi e peso sem plataforma de colheita de $10,54 \mathrm{Mg}$. O trator utilizado possuía pneus dianteiros tipo 14.924R1 e traseiros tipo 18.4-34R1, pressão de insuflação de 16 psi e com peso de embarque lastrado de 5,24 Mg.

A definição das zonas de rendimento baseou-se no rendimento monitorado nos anos de 2005, 2006 e 2007. Para cada safra agrícola, foram gerados mapas de

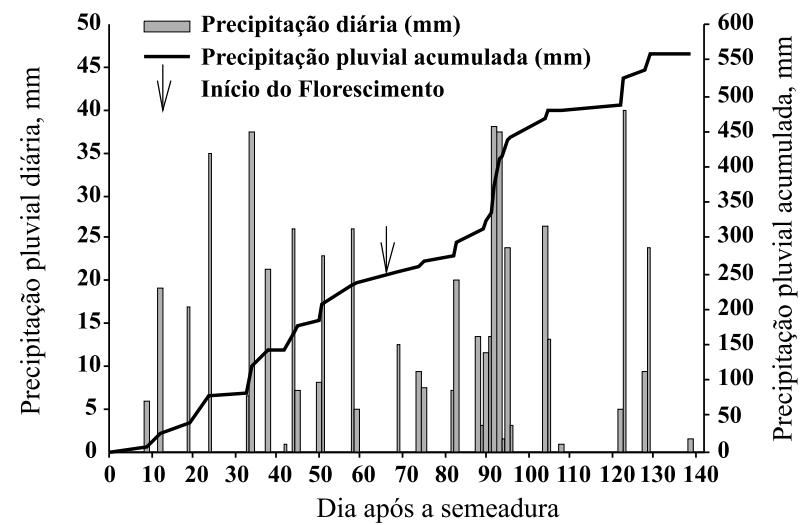

Figura 1. Precipitação pluvial diária e acumulada no município de Victor Graeff, RS, durante o ciclo da cultura da soja. Fonte: Cotrijal.

rendimentos e determinou-se o rendimento médio. Em seguida, foram determinadas três zonas de rendimento, segundo método proposto por Molin (2002), sendo consideradas como zona de alto rendimento (ZA) as áreas que obtiveram rendimento $>105 \%$ do rendimento médio. Já as áreas que se encontravam entre 95 e $105 \%$ do rendimento médio foram consideradas como zonas de médio rendimento (ZM), e as regiões com $<95 \%$, como zona de baixo rendimento (ZB). Os dados irreais (coordenadas repetidas e valores de rendimento discrepantes) foram filtrados.

$\mathrm{O}$ experimento foi implantado na $\mathrm{ZB}$ seguindo o delineamento experimental de blocos casualizados. Os seguintes tratamentos foram investigados: (a)

Quadro 1. Histórico do rendimento das zonas de manejo e dos teores de nutrientes no solo na área estudada

\begin{tabular}{|c|c|c|c|c|}
\hline \multirow[b]{2}{*}{ Zona de rendimento } & \multicolumn{4}{|c|}{ Ano Agrícola/Cultura } \\
\hline & 2005/06 - Soja & 2006/07 - Soja & 2007/08 - Milho & 2008/09 - Soja \\
\hline & \multicolumn{4}{|c|}{ Rendimento $\left(\mathrm{kg} \mathrm{ha}^{-1}\right)$} \\
\hline Média Geral & 3600 & 3120 & 7680 & 3618 \\
\hline $\mathrm{ZB}$ & 2668 & 2782 & 5913 & 2708 \\
\hline $\mathrm{ZM}$ & 3537 & 3610 & 7679 & 3606 \\
\hline \multirow[t]{2}{*}{$\mathrm{ZA}$} & 4246 & 4143 & 9413 & 4298 \\
\hline & \multicolumn{4}{|c|}{ Área (ha) } \\
\hline $\mathrm{ZB}$ & 14,66 & 16,24 & 20,25 & 13,49 \\
\hline $\mathrm{ZM}$ & 20,97 & 17,16 & 9,63 & 18,70 \\
\hline \multirow[t]{2}{*}{$\mathrm{ZA}$} & 15,06 & 17,22 & 20,74 & 18,43 \\
\hline & \multicolumn{4}{|c|}{ Teores médios } \\
\hline $\mathrm{P}\left(\mathrm{mg} \mathrm{dm}{ }^{-3}\right)$ & 27,0 & nd & 28,1 & 25,8 \\
\hline $\mathrm{K}\left(\mathrm{cmol}_{\mathrm{c}} \mathrm{dm}^{-3}\right)$ & 212 & nd & 219 & 240 \\
\hline $\mathrm{MO}\left(\mathrm{g} \mathrm{kg}^{-1}\right)$ & 2,9 & nd & 2,2 & 2,2 \\
\hline pH (água) & 6,0 & nd & 5,5 & 5,9 \\
\hline $\mathrm{Ca}\left(\mathrm{cmol}_{\mathrm{c}} \mathrm{dm}^{-3}\right)$ & 6,3 & nd & 5,8 & 5,0 \\
\hline $\mathrm{Mg}\left(\mathrm{cmol}_{\mathrm{c}} \mathrm{dm}^{-3}\right)$ & 2,1 & nd & 2,8 & 1,8 \\
\hline $\mathrm{V}(\%)$ & nd & nd & nd & 79 \\
\hline
\end{tabular}

ZB: zona de baixo rendimento; ZM: zona de médio rendimento; ZA: zona de alto rendimento; nd: não disponível. 
escarificação convencional com profundidade fixa de 0,30 m (EC); (b) escarificação sítio-específico com equipamento $\mathrm{Fox}^{\circledR}$ com profundidade fixa de $0,30 \mathrm{~m}$ (ESEF); (c) escarificação sítio-específico com equipamento Fox $^{\circledR}$ com profundidade de atuação variável $(0,10$ a $0,30 \mathrm{~m})$ em função da resistência máxima à penetração (ESEV); e (d) controle sem escarificação (SE). Ainda, foi avaliada uma faixa na ZA sem escarificação (ZA). Os tratamentos foram implantados sem repetição em faixas paralelas de $100 \times 20$ m de largura, totalizando uma área experimental de $10.000 \mathrm{~m}^{2}$.

As escarificações foram realizadas no dia 22 de novembro de 2008, antecedendo uma semana a semeadura da cultura da soja, quando o solo encontrava-se com baixa umidade $\left(14 \mathrm{~m}^{3} \mathrm{~m}^{-3}\right)$, na profundidade de 0-0,20 m. O escarificador convencional atuou com sete hastes espaçadas de 0,40 m. O escarificador sítio-específico e a profundidade fixa atuaram com nove hastes desencontradas, com espaçamento de 0,30 m. A resistência à penetração e a umidade do solo foram determinadas em cinco pontos por tratamento, espaçados de $20 \mathrm{~m}$ entre si. Em cada ponto foram feitas 10 repetições, utilizando um penetrômetro digital com leituras a cada $0,01 \mathrm{~m}$ até a profundidade de $0,40 \mathrm{~m}$.

Os atributos físicos (densidade do solo, macroporosidade, microporosidade e porosidade total) foram investigados em todos os tratamentos nas seguintes profundidades: 0,0-0,05, 0,05-0,10, 0,100,15 e $0,15-0,20 \mathrm{~m}$, com nove repetições por tratamento, mantendo um espaçamento de $10 \mathrm{~m}$ entre repetições. A densidade do solo foi determinada por meio de amostras indeformadas, seguindo método descrito em Embrapa (1997). Para isso, abriram-se pequenas trincheiras, a fim de que os anéis com volume conhecido $(0,03 \mathrm{~m}$ de altura e $0,05 \mathrm{~m}$ de diâmetro) fossem introduzidos no solo. Com esses anéis, foram determinadas a macroporosidade, a microporosidade e a porosidade total, bem como a umidade volumétrica do solo. As avaliações de infiltração de água no solo foram realizadas com 10 repetições por tratamento, dentro de um raio de $5 \mathrm{~m}$ em torno do ponto georeferenciado. Nessa avaliação foi utilizado o método dos duplos anéis concêntricos, seguindo o método de Bouwer (1986) e da Embrapa (1997). O infiltrômetro confeccionado é semelhante ao descrito por Siqueira \& Denardin (1985) e adaptado por Lanzanova et al. (2007). No cilindro externo, a lâmina de água de 0,05 m foi mantida, manualmente, no mesmo nível do anel interno. As leituras foram tomadas em intervalos de tempo regulares: 5, 10, 15, 20,30, 45, 60, 90 e $120 \mathrm{~min}$ após o início do teste. As avaliações dos atributos físicos foram realizadas em três épocas (nove dias antecedendo a implantação do experimento, 14 dias após a escarificação e nove dias após o final do ciclo da cultura da soja). As épocas foram estabelecidas em função das condições climáticas, da demanda de mão de obra e de tempo para realização das avaliações e da minimização de danos à cultura da soja. Quando da realização dos testes de infiltração, a umidade volumétrica do solo era de 20,5, 19,7 e 20,4 $\mathrm{m}^{3} \mathrm{~m}^{-3}$ na profundidade de 0 0,20 m, respectivamente, nas três épocas de avaliação, estando dentro da faixa de friabilidade.

Na determinação da cobertura vegetal foi utilizado o método da trena marcada (Laflen et al., 1981). Em uma extensão de $10 \mathrm{~m}$ foram colocados marcadores em intervalos regulares de $0,10 \mathrm{~m}$. No campo, essa trena foi estendida transversalmente à linha de operação dos escarificadores e da semeadora. Para determinação da cobertura, procedeu-se à contagem dos pontos com solo descoberto ou com cobertura vegetal (palha ou planta de soja), determinando assim a percentagem de cobertura do solo. Essa avaliação foi realizada no estádio vegetativo $V_{1}$ da escala fenológica da soja.

A colheita das culturas da soja e do milho no período de 2005 a 2009 foi realizada com uma colhedora mecânica equipada com sensor de rendimento, instalado no elevador de grãos. Após a colheita, os dados foram tabulados, utilizando-se o programa Microsoft Office Excel 2007® e o CR-Campeiro 5 (Giotto et al., 2004), eliminando, por meio de filtragens, as principais fontes de erros (Menegatti \& Molin, 2004). Os resultados foram expressos com umidade de grãos ajustada para $13 \mathrm{~kg} \mathrm{~kg}^{-1}$. Para avaliação do rendimento do experimento, cada tratamento foi colhido separadamente, e o peso, determinado em balança. Determinou-se ainda, em nove pontos por tratamento, o número de plantas em 2,0 m lineares, bem como o número de vagens por planta e o peso de 100 grãos.

Os dados foram submetidos à análise de variância pelo programa computacional SISVAR 5.0 (Ferreira, 2007), e as médias, comparadas pelo teste de Tukey $(\mathrm{p}<0,05)$

\section{RESULTADOS E DISCUSSÃO}

\section{Caracterização inicial dos atributos físicos do solo}

A caracterização dos atributos físicos do solo foi feita em zonas de rendimento estabelecidas a partir de três mapas de colheita sobrepostos. A densidade do solo, com exceção da camada de $0,15-0,20 \mathrm{~m}$, foi semelhante entre as zonas de rendimento (Quadro 2). Já a porosidade total foi um atributo mais sensível às zonas de rendimento, sendo a $\mathrm{ZB}$ inferior à $\mathrm{ZA}$ na maioria das camadas investigadas, com exceção da primeira e da profundidade de $0-20 \mathrm{~cm}$. Quanto à macroporosidade, as zonas de rendimento não apresentaram diferenças, em parte devido ao elevado CV e à imprecisão experimental para esse atributo fato também anteriormente reportado por Câmara \& Klein (2005). À exceção da primeira camada amostrada, todas as demais apresentaram valores de macroporosidade abaixo dos estabelecidos como críticos 
Quadro 2. Densidade do solo (Ds), macroporosidade (Ma), microporosidade (Mi) e porosidade total (Pt) em diferentes zonas de rendimento na implantação do experimento

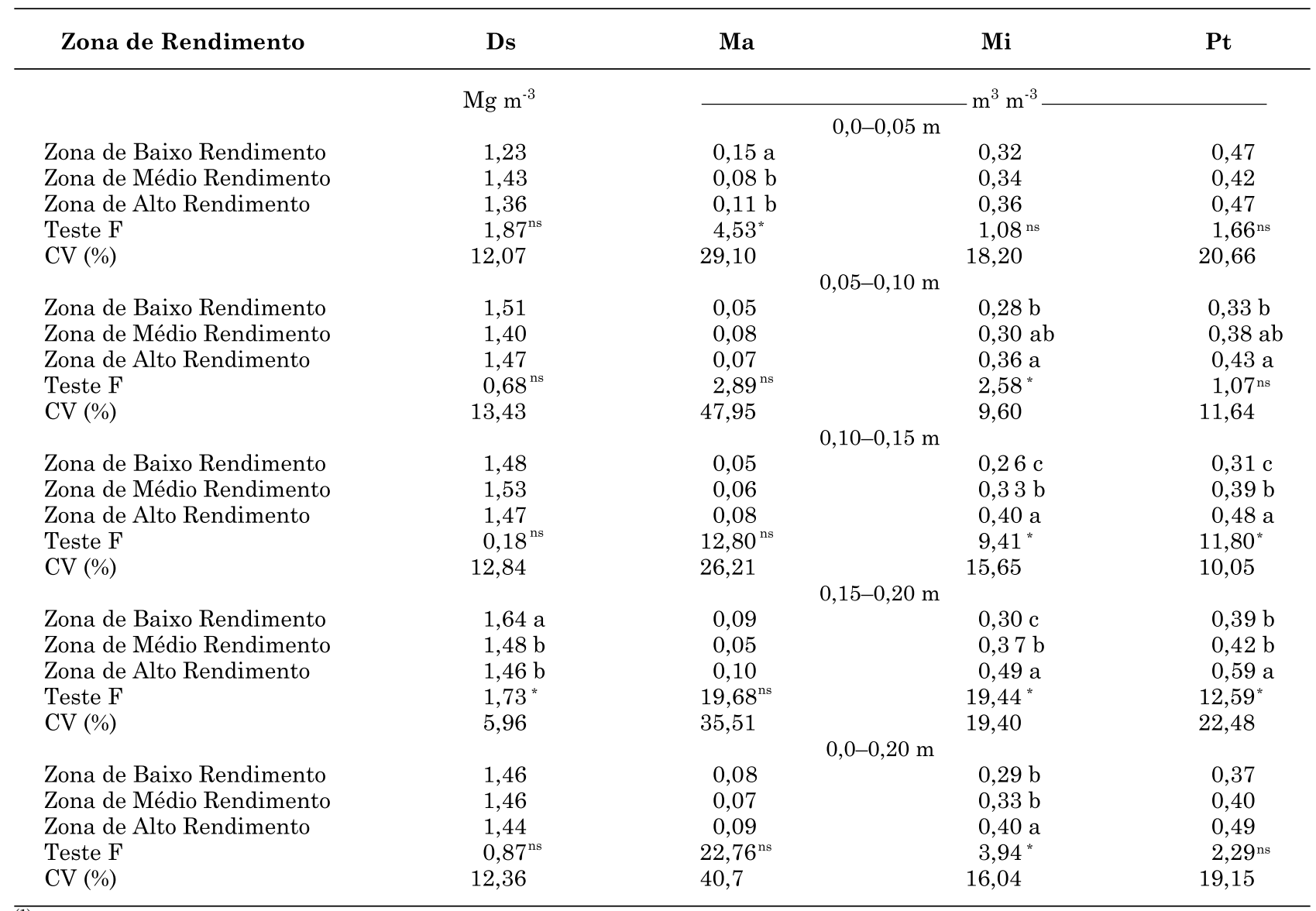

${ }^{(1)}$ Médias seguidas por letras distintas, na mesma coluna e profundidade, diferem pelo teste de Tukey (p<0,05). ${ }^{\text {ns }}$ : Teste $\mathrm{F}$ não significativo. ${ }^{*}$ Teste $\mathrm{F}$ significativo $(\mathrm{p}<0,05)$.

$\left(<0,10 \mathrm{~m}^{3} \mathrm{~m}^{-3}\right)$ (Silva et al., 1994). Assim, os valores de macroporosidade observados são considerados limitantes à infiltração de água e ao adequado suprimento de oxigênio às raízes. No que se refere à microporosidade, constatou-se, nas profundidades de 0,10-0,15 e 0,15-0,20 m, que os valores da ZM e ZA foram superiores aos da ZB.

Neste trabalho, um dos pressupostos para a escolha da área agrícola era de que ela apresentasse compactação do solo, segundo a avaliação do produtor e do seu assistente técnico. Esse fato foi confirmado, uma vez que na profundidade de 0,15-0,20 m a ZB mostrou densidade do solo $12 \%$ maior e porosidade total $34 \%$ menor do que a de ZA (Quadro 2). No SPD, existe a tendência de aumento da densidade nas camadas mais superficiais do solo, conforme reportado anteriormente por Tormena et al. (1998) e Silva et al. (2000). Assim, Pott \& De Maria (2003) reportaram que, em três solos investigados, houve diminuição da densidade e incremento da porosidade com o aumento da profundidade. Contrariamente, neste trabalho, verificou-se na $\mathrm{ZB}$ o incremento da densidade do solo e o decréscimo da porosidade à medida que a profundidade aumentou, refletindo, provavelmente, o efeito do trânsito e da operação de máquinas agrícolas. Segundo Secco et al. (2005), o valor crítico de densidade para solos com teores de argila entre 200 e $550 \mathrm{~g} \mathrm{~kg}^{-1}$ é $1,55 \mathrm{Mg} \mathrm{m}^{-3}$; portanto, na $\mathrm{ZB}$, na profundidade de $0,15-0,20 \mathrm{~m}$, a densidade foi $6 \%$ superior à crítica. De maneira geral, na ZA, nenhum dos indicadores físicos investigados apresentou valores superiores aos críticos.

Os resultados obtidos nessa caracterização inicial foram similares aos encontrados anteriormente por Amado et al. (2009) em duas áreas comerciais sob SPD, em Latossolos do Planalto do RS. Esses autores também reportaram maiores valores de densidade do solo e menores de macroporosidade e porosidade total na $\mathrm{ZB}$ em relação à $\mathrm{ZA}$, e com a mesma tendência de agravamento dessa situação à medida que a profundidade aumentava, sugerindo que a deterioração da qualidade física da camada subsuperficial tenha contribuído para a variabilidade do rendimento de grãos. Essa hipótese também pode ser válida para este trabalho, uma vez que a área apresentava elevada fertilidade do solo, com valores de $\mathrm{pH}, \mathrm{Ca}, \mathrm{Mg}, \mathrm{P}$ e K 
acima dos teores críticos estabelecidos pela CQFSRS/ SC (2004) (Quadro 1).

\section{Escarificação mecânica e a alteração da quali- dade física do solo}

Aproximadamente 70 dias após a escarificacão, coincidindo com o estádio de florescimento da soja, verificou-se, na profundidade de $0-0,20 \mathrm{~m}$, que os atributos físicos do solo não foram restritivos ao desenvolvimento vegetal (Quadro 3). Em especial, nessa avaliação, a densidade do solo e a macroporosidade distinguiram-se em relação à caracterização inicial. $\mathrm{Na}$ profundidade de 0-20 cm, o tratamento ESEV apresentou incremento de $33 \%$ na macroporosidade em relação ao SE. No entanto, analisando os atributos físicos por camadas individuais, observou-se que as maiores alterações na densidade do solo, macroporosidade e microporosidade, em relação ao tratamento controle, ocorreram na profundidade de 0-0,05 m, sugerindo uma interação entre o sistema radicular da soja e a região escarificada no solo. Além disso, a maior atividade da fauna do solo e os ciclos de umedecimento e secagem nesta camada podem ter contribuído para os resultados observados. Anteriormente, Câmara \& Klein (2005) reportaram que a densidade do solo sob SPD diminuiu com a escarificação, porém a porosidade total e a macroporosidade não foram alteradas. Já na profundidade de $0,15-0,20 \mathrm{~m}$, em que a qualidade física era inferior, no florescimento da soja não foi observado efeito de melhoria dos atributos físicos do solo (Quadro 3). A efemeridade das alterações na qualidade física induzida pela escarificação mecânica em solos argilosos havia sido anteriormente registrada em outros trabalhos (Secco \& Reinert 1997; Lima et al., 2006), sendo dependente da precipitação acumulada e da intensidade de mobilização do solo pelo escarificador (Busscher et al., 2002). Nicoloso et al. (2008) sustentaram que a presença de raízes de culturas de cobertura cultivadas após a operação pode prolongar o efeito da escarificação mecânica, fato que pode explicar a melhoria da qualidade física restrita às duas primeiras profundidades investigadas neste trabalho, nas quais as raízes de soja concentraramse.

\section{Escarificação mecânica e a cobertura do solo remanescente}

A manutenção da cobertura do solo por resíduos vegetais é essencial para o controle da erosão (Eltz et al., 1989; Bertol \& Fischer, 1997) e incremento da disponibilidade de água às plantas (Bragagnolo \& Mielniczuk, 1990; Dalmago et al., 2009). A cobertura do solo no tratamento SE foi próxima a $80 \%$, sendo semelhante à encontrada na maioria das lavouras sob SPD no Sul do Brasil.

Os resultados apresentados na figura 2 evidenciaram a eficiência do escarificador sítioespecífico em manter a cobertura do solo. Nos tratamentos em que esse equipamento foi utilizado, a
Quadro 3. Densidade do solo (Ds), macroporosidade (Ma), microporosidade (Mi) e porosidade total (Pt) na zona de baixo rendimento(ZB), no período do pleno florescimento da soja, em um Latossolo Vermelho distrófico

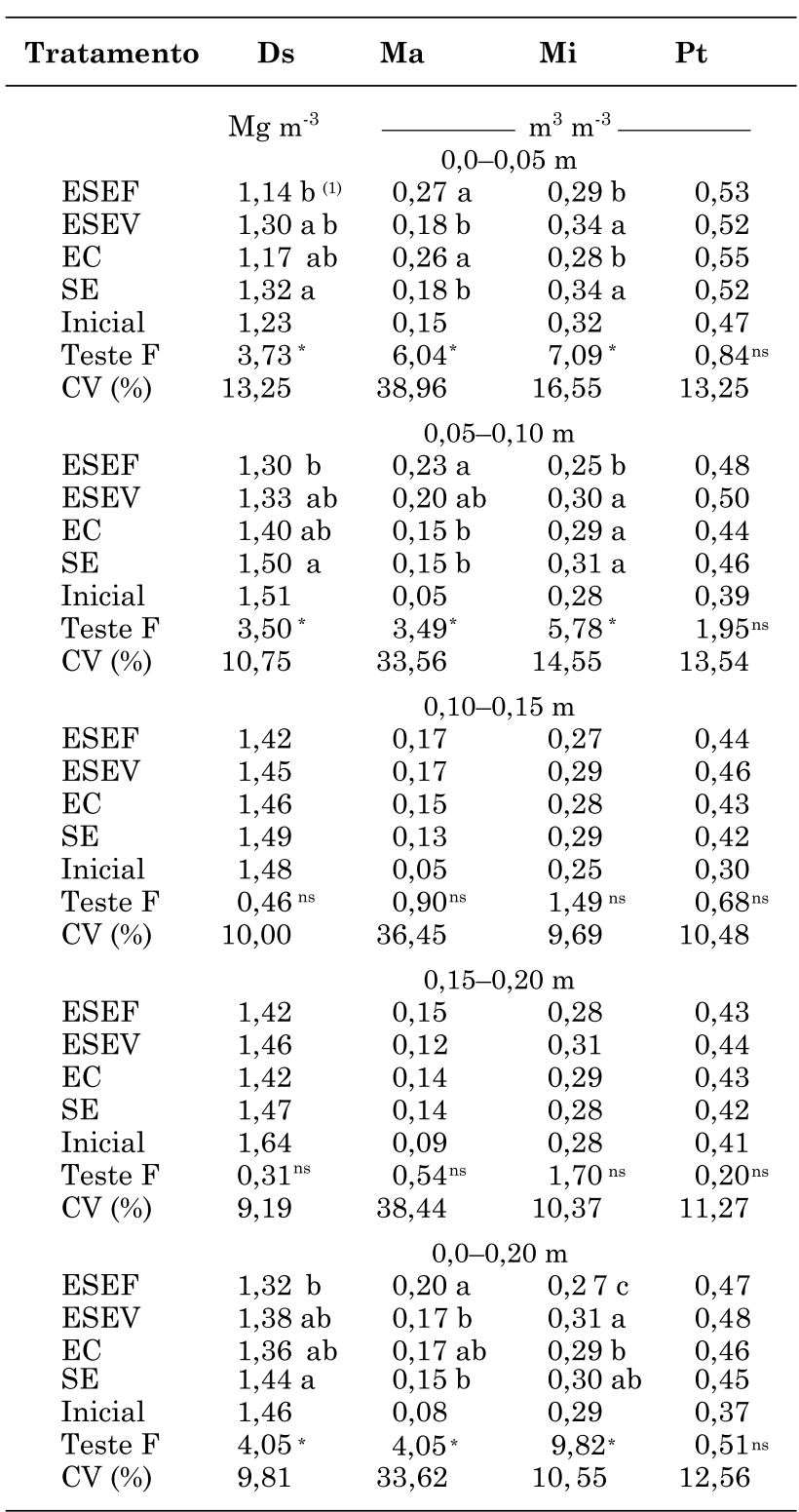

ESEF: escarificador sítio-específico em profundidade fixa; ESEV: escarificador sítio-específico em profundidade variada; EC: escarificador convencional; SE: controle sem escarificação. (1) Médias seguidas por letras distintas, na mesma coluna e profundidade, diferem pelo teste de Tukey $(p<0,05)$. ${ }^{\text {ns }}$ : Teste $\mathrm{F}$ não significativo. *: Teste $\mathrm{F}$ significativo $(\mathrm{p}<0,05)$.

cobertura do solo foi aproximadamente três vezes superior à do escarificador convencional. Segundo Bertol \& Fischer (1997), com $60 \%$ de cobertura do solo, valor obtido nos tratamentos com escarificador sítio-específico (Figura 2), verifica-se redução de 80 \% nas perdas de solo. Considerando a cobertura do solo no tratamento controle SE como de $100 \%$, a eficiência 


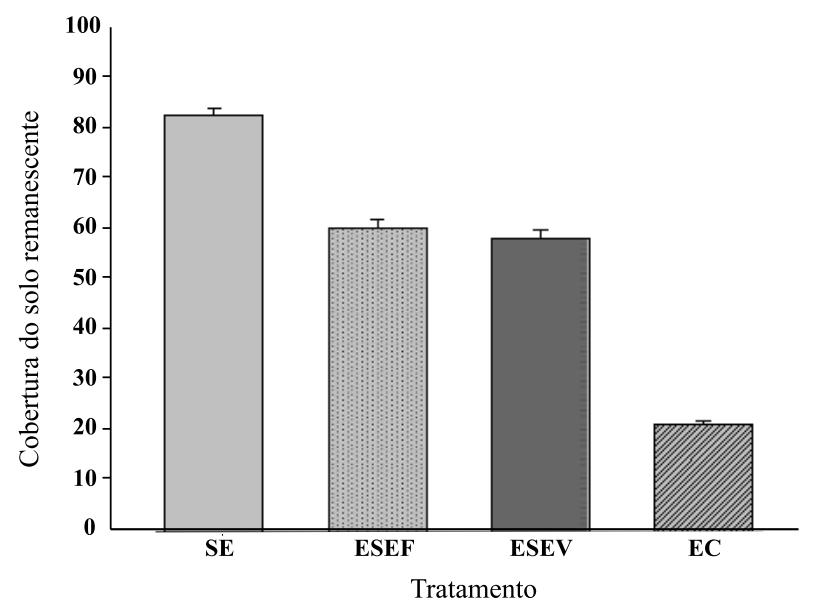

Figura 2. Cobertura do solo remanescente após a escarificação mecânica. ESEF: escarificador sítio-específico em profundidade fixa; ESEV: escarificador sítio-específico em profundidade variada; EC: escarificador convencional; SE: controle sem escarificação, sendo cada tratamento acompanhado pela barra de erro.

relativa na manutenção da cobertura foi de $72,70 \mathrm{e}$ $25 \%$ para ESEF, ESEV e EC, respectivamente.

A preservação da cobertura do solo pelo escarificador sítio-específico está relacionada às características do equipamento, com destaque para a presença de discos de corte na parte frontal, alinhados com as hastes, menor inclinação e reduzida largura das hastes. Os discos, ao fracionarem os resíduos vegetais, evitaram que uma maior quantidade de resíduos fosse incorporada ao solo durante a operação. O menor espaçamento entre as hastes de trabalho $(0,30 \mathrm{~m})$ ocasionou a formação de torrões menores, que posteriormente favoreceram a operação de semeadura. Já o EC induziu a formação de torrões maiores e ocasionou maior incorporação de resíduos vegetais.

\section{Escarificação mecânica e a infiltração de água no solo}

O incremento da infiltração da água é o principal argumento para a escarificação em áreas de SPD. Neste trabalho, os valores de infiltração acumulada nos tratamentos variaram de 35 a $268 \mathrm{~mm}$ (Figura 3). O menor volume de água infiltrado no solo foi verificado após o manejo da cultura de cobertura (aveiapreta), e o maior, após a escarificação (14 dias após a operação). No tratamento SE observou-se incremento linear da infiltração com o tempo (Figura 3), estando esse resultado coerente com o incremento observado na macroporosidade (Quadro 4). Câmara \& Klein (2005) reportaram que o SPD sem escarificação apresentou $80 \mathrm{~mm}$ de infiltração, valor próximo ao observado no final do ciclo da soja neste trabalho (97 mm). Na avaliação logo após a escarificação, a lâmina de água infiltrada no solo, ao final dos $120 \mathrm{~min}$, foi semelhante entre os tratamentos EC e ESEV, com 266 e $262 \mathrm{~mm}$, respectivamente. Esses valores foram aproximadamente quatro vezes superiores ao observado no tratamento controle. Anteriormente, Eltz et al. (1989) e Câmara \& Klein (2005) também reportaram incrementos na infiltração de água de quatro a cinco vezes após a escarificação. Esses autores atribuíram o resultado à alteração na estrutura do solo induzida pela escarificação, com diminuição da densidade e incremento da condutividade hidráulica.

Logo após a colheita da cultura da soja, observaram-se reduções na infiltração de 100 e $180 \mathrm{~mm}$, nos tratamentos EC e ESEF, respectivamente. Esses valores representam reduções, sete meses após a escarificação, de 38 e 70 \% na infiltração, para os mesmos tratamentos anteriores. Esses decréscimos provavelmente estão associados à reacomodação das partículas de solo verificada durante o ciclo da cultura (Lima et al., 2006). No tratamento EC, o efeito da escarificação foi mais persistente, provavelmente devido à maior mobilização do solo e ao maior tamanho dos torrões formados. Já nos tratamentos com escarificador sítio-específico, após a colheita da soja, já não havia diferença na infiltração em relação ao SE. A curta duração do efeito da escarifação foi reportada por Secco \& Reinert (1997) e Nicoloso et al. (2008), os quais observaram que o efeito de melhoria na qualidade física não persistiu além de nove a dez meses, em solos com textura argilosa.

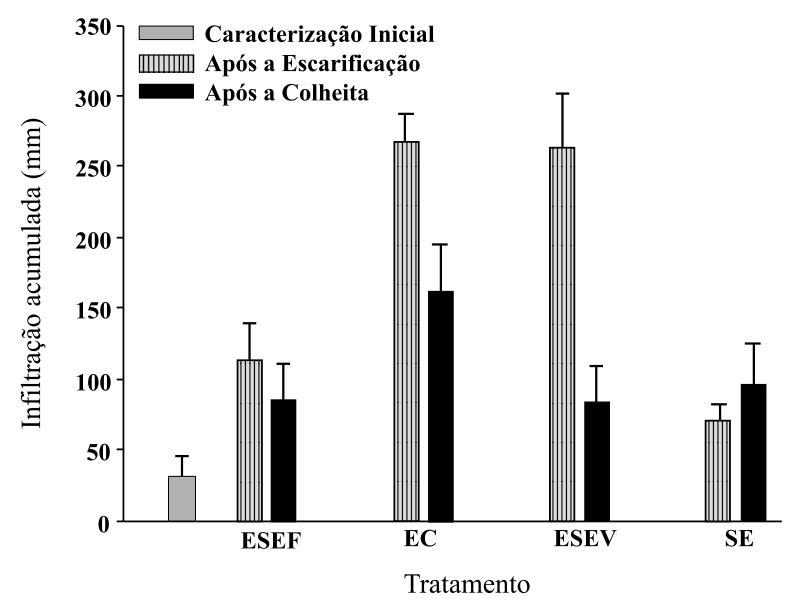

Figura 3. Infiltração acumulada de água no solo em 120 min, obtida em três diferentes épocas (caracterização inicial, após a escarificação mecânica e após a colheita) com infiltrômetro de duplos anéis concêntricos. ESEF: escarificador sítio-específico em profundidade fixa; ESEV: escarificador sítio-específico em profundidade variada; EC: escarificador convencional; SE: controle sem escarificação. 
Quadro 4. Número de plantas por metro quadrado, número de vagens por planta e por metro quadrado e peso de 100 grãos, em função dos diferentes tipos de escarificadores investigados

\begin{tabular}{|c|c|c|c|c|c|c|c|c|}
\hline \multirow{2}{*}{ Tratamento } & \multirow{2}{*}{$\begin{array}{c}\text { População } \\
\text { plantas }\end{array}$} & \multicolumn{6}{|c|}{ Número de vagens } & \multirow{2}{*}{$\begin{array}{c}\text { Peso de } \\
100 \text { grãos }\end{array}$} \\
\hline & & 1 grão & 2 grãos & 3 grãos & 4 grãos & Planta & Número/m $\mathbf{m}^{2}$ & \\
\hline & $\mathrm{m}^{2}$ & & & & & & & $\mathrm{~g}$ \\
\hline ESEF & 15 & $5,00 \mathrm{ab}^{(1)}$ & $25,56^{\mathrm{ns}}$ & $26,89^{\mathrm{ns}}$ & $1,16^{\mathrm{ns}}$ & $58,60^{\mathrm{ns}}$ & $905,04^{\mathrm{ns}}$ & $20,14 \mathrm{a}$ \\
\hline ESEV & 16 & $5,90 \mathrm{ab}$ & 24,77 & 25,70 & 1,30 & 57,67 & 903,44 & $19,76 \mathrm{a}$ \\
\hline $\mathrm{EC}$ & 15 & $6,38 \mathrm{a}$ & 27,64 & 28,94 & 1,16 & 64,12 & 936,15 & $19,65 \mathrm{a}$ \\
\hline SE & 16 & $4,20 \mathrm{~b}$ & 21,90 & 24,84 & 1,18 & 52,12 & 819,74 & $18,98 \mathrm{ab}$ \\
\hline $\mathrm{ZA}$ & 17 & $5,20 \mathrm{ab}$ & 27,30 & 28,50 & 1,30 & 62,30 & 1052,60 & $17,61 \mathrm{~b}$ \\
\hline CV (\%) & 14,23 & 29,20 & 18,40 & 18,75 & 5,20 & 58,40 & 17,30 & 3,90 \\
\hline
\end{tabular}

(1) Médias seguidas por letras distintas, na mesma coluna, diferem pelo teste de Tukey $(\mathrm{p}<0,05)$. ${ }^{\mathrm{ns}}$ : Teste $\mathrm{F}$ não significativo. Peso grãos: massa de 100 grãos; ESEF: escarificador sítio-específico em profundidade fixa; ESEV: escarificador sítio-específico em profundidade variada; EC: escarificador convencional; SE: controle sem escarificação; ZA: zona de alto rendimento.

\section{Escarificação mecânica e o rendimento da soja}

O rendimento de soja nos tratamentos investigados variou de 3.480 a $3.833 \mathrm{~kg} \mathrm{ha}^{-1}$, refletindo as condições climáticas favoráveis e as boas práticas de manejo adotadas na área agrícola. Esses valores, embora elevados, são próximos aos rendimentos médios obtidos nessa lavoura em duas safras anteriores $\left(3.600 \mathrm{~kg} \mathrm{ha}^{-1}\right.$ em 2005/06 e $3.618 \mathrm{~kg} \mathrm{ha}^{-1}$ em 2008/09) (Quadro 1).

Nem sempre as alterações nos atributos físicos do solo proporcionadas pela escarificação mecânica do solo refletem-se em incremento no rendimento das culturas (Bayer et al., 1998). Assim, embora o tratamento ESEV tenha apresentado o maior rendimento (3.833 $\mathrm{kg} \mathrm{ha}^{-1}$ ) e tenha sido 6,4 \% superior ao SE, não houve diferença estatística entre eles (Figura 4). Recentemente, Nicoloso et al. (2008) reportaram que o rendimento de soja após a escarificação, combinada com o uso de culturas de cobertura, alcançou $3.730 \mathrm{~kg} \mathrm{ha}^{-1}$, sendo aproximadamente $7 \%$ superior ao tratamento $\mathrm{SE}$, porém também sem diferença estatística. Anteriormente, Secco et al. (2005) também não encontraram diferença significativa no rendimento de soja para diferentes formas de manejo do solo, com rendimentos variando de 2.830 a $2.710 \mathrm{~kg} \mathrm{ha}^{-1}$ para o SPD contínuo e SPD escarificado, respectivamente. Por sua vez, Bertol \& Fischer (1997) relataram que o preparo do solo proporcionou maior rendimento de soja, em relação ao SPD contínuo.

Neste trabalho, constatou-se que o grau de compactação, expresso pelos valores de densidade do solo acima e macroporosidade abaixo dos limites críticos na profundidade de 0,15-0,20 m (Quadro 3), não comprometeu, como esperado, o rendimento da cultura da soja. Assim, o tratamento SE, na ZB, apresentou rendimento semelhante ao da ZA (Figura 4). Por outro lado, a melhoria na qualidade física do solo proporcionada pela escarificação mecânica (Quadro 3), sob condições favoráveis de precipitação (Figura 1), também não aumentou o rendimento da soja (Figura 4). Neste estudo, a precipitação acumulada apresentou aumento acentuado com o avanço do ciclo da cultura, passando de $250 \mathrm{~mm}$, acumulados até o início do florescimento, para um total de $560 \mathrm{~mm}$ na maturação (Figura 1). Esse incremento pluvial foi coincidente com a época de maior demanda da cultura, uma vez que estiagens durante o período reprodutivo (florescimento e enchimento de grãos) causam drásticas reduções no rendimento, devido a abortamento de flores e de legumes, menor período de florescimento, menor número de grãos por legume, menor período de enchimento de grãos, diminuição da qualidade de grãos e aceleração da senescência foliar (Sionit \& Kramer, 1977; De Souza et al., 1997). A interação entre as condições climáticas

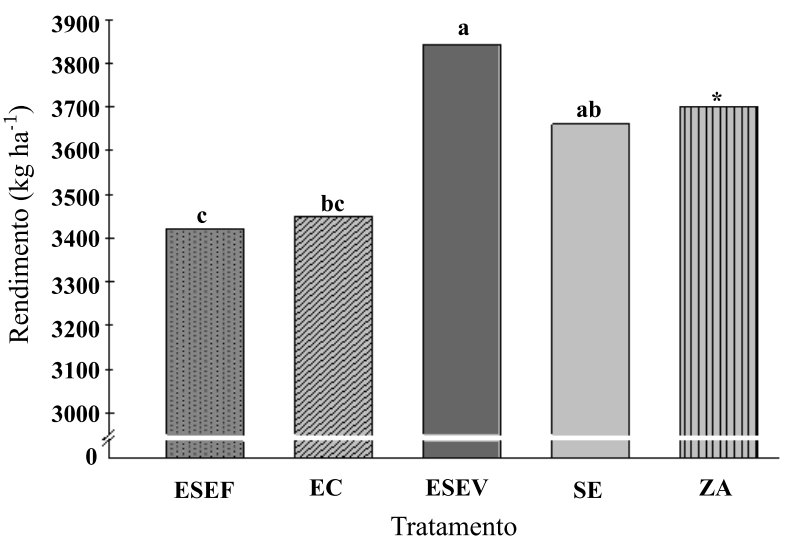

Figura 4. Rendimento médio de grãos de soja nos tratamentos implantados na zona de baixo rendimento. *: Zona de alto rendimento, tratamento-referência; ESEF : escarificador sítio-específico em profundidade fixa; ESEV : escarificador sítio-específico em profundidade variada; EC : escarificador convencional; SE : controle sem escarificação. Médias seguidas pela mesma letra não diferem estatisticamente entre si pelo teste de Tukey $(p<0.05)$. 
e os valores críticos de atributos físicos do solo deve ser investigada em futuros trabalhos. Anteriormente, Beutler et al. (2007) reportaram a interação entre irrigação e compactação do solo, sustentando que a irrigação pode amenizar o decréscimo no rendimento previsto com base na inferior qualidade física do solo.

A maioria dos componentes de rendimento da soja não foi influenciada pela escarificação mecânica em relação ao tratamento controle SE (Quadro 4), à semelhança do verificado para o rendimento, suportando a hipótese que, nessa safra. a inferior qualidade física do solo no tratamento SE não mostrouse deletéria ao rendimento da cultura.

$\mathrm{Na}$ comparação dos tipos de escarificadores, constatou-se que o ESEF foi superior ao EC, com incremento de $12 \%$ no rendimento da soja. Nas profundidades de 0-0,05 e 0,05-0,10 m, o solo sob ESEF, geralmente, apresentou menor densidade e maior macroporosidade do que sob EC. Além disso, proporcionou cobertura do solo três vezes superior à do EC, embora a infiltração de água tenha sido semelhante entre esses tratamentos na avaliação realizada logo após a operação e, inclusive, maior no EC do que no ESEF, na avaliação do final do ciclo da cultura. Esses resultados sustentam que o escarificador sítio-específico pode ser uma alternativa eficiente em relação ao escarificador convencional em áreas sob SPD.

\section{CONCLUSÕES}

1. A zona de baixo rendimento apresentou qualidade física do solo inferior, expressa pela densidade do solo e porosidade total superior e inferior, respectivamente, aos valores críticos na profundidade de 0,15-0,20 m, condicionando baixa infiltração de água no solo.

2. Nos tratamentos escarificador convencional e sítio-específico à taxa variada, o aumento na infiltração de água no solo foi quatro vezes superior em relação ao controle. No entanto, esse efeito positivo da escarificação mecânica foi temporário, sendo anulado sete meses após a operação do solo.

3. Sob elevada precipitação durante o ciclo da cultura e estado moderado de compactação do solo, a alteração na qualidade física proporcionada pela escarificação mecânica não influenciou o rendimento da soja em relação ao controle.

4. Na comparação dos escarificadores, o sítioespecífico à taxa variada destacou-se por apresentar $40 \%$ a mais de cobertura do solo remanescente e proporcionar $12 \%$ de incremento no rendimento de soja, em relação ao convencional.

\section{AGRADECIMENTOS}

Ao sr. Volnei Koeche e ao departamento técnico COTRIJAL, pela cessão da área experimental e realização dos tratos culturais. Ao $\mathrm{CNPq}$, pela concessão de bolsas e pelo auxílio à pesquisa. À STARA e à Massey Ferguson, pela cessão de equipamentos e de equipe técnica para acompanhamento de atividades de campo.

\section{LITERATURA CITADA}

ABREU, S.L.; REICHERT, J.M. \& REINERT, D.J. Escarificação mecânica e biológica para a redução da compactação em Argissolo franco arenoso em plantio direto. R. Bras. Ci. Solo, 28:519-531, 2004.

AMADO, T.J.C.; PES, L.C.; LEMAINSKI, C.L. \& SCHENATO, R.B. Atributos químicos e físicos de Latossolos e sua relação com o rendimento de milho e feijão irrigados. $R$. Bras. Ci. Solo, 33:831-843, 2009.

ARAUJO, M.A.; TORMENA, C.A.; INOUE, T.T. \& COSTA, A.C.S. Efeitos da escarificação na qualidade física de um Latossolo Vermelho distroférrico após treze anos de semeadura direta. R. Bras. Ci. Solo, 28:495-504, 2004.

BAYER, C.; MIELNICZUK, J. \& PAVINATO, A. Sistemas de manejo do solo e seus efeitos sobre o rendimento do milho. Ci. Rural, 28:23-28, 1998.

BERTOL, O.J. \& FISCHER, I.I. Semeadura direta versus sistemas de preparo reduzido: Efeito na cobertura do solo e no rendimento da cultura da soja. Eng. Agríc, 17:87-96, 1997.

BEUTLER, A.N. \& CENTURION, J.F. Compactação do solo no desenvolvimento radicular e na produtividade da soja. Pesq. Agropec. Bras., 39:581-588, 2004.

BEUTLER, A.N.; CENTURION, J.F.; CENTURION, M.A.P.C.; LEONEL, C.L.; SÃO JOÃO, A.C.G. \& FREDDI, O.S. Intervalo hídrico ótimo no monitoramento da compactação e da qualidade física de um Latossolo Vermelho cultivado com soja. R. Bras. Ci. Solo, 31:1223$1232,2007$.

BOUWER, H. Intake rate: Cylinder infiltrometer. In: KLUTE, A., ed. Methods of soil analysis I, physical and mineralogical methods. 2.ed. Madison, ASA/SSSA, 1986. p.825-844.

BRAGAGNOLO, N. \& MIELNICZUK, J. Cobertura do solo por palha de trigo e seu relacionamento com a temperatura e umidade do solo. R. Bras. Ci. Solo, 14:369374,1990

BUSSCHER, W.J.; BAUER, P.J. \& FREDERICK, J.R. Recompaction of a coastal loamy sand after deep tillage as a function of subsequent cumulative rainfall. Soil Tillage Res., 68:49-57, 2002. 
CAMARA, R.K. \& KLEIN, V.A. Escarificação em plantio direto como técnica de conservação do solo e da água. R. Bras. Ci. Solo, 29:789-796, 2005.

COMISSÃO DE QUÍMICA E FERTILIDADE DO SOLO CQFS/RS-SC. Manual de adubação e calagem para os estados do Rio Grande do Sul e Santa Catarina. Porto Alegre, Sociedade Brasileira de Ciência do Solo/Núcleo Regional Sul, 2004. 400p.

DALMAGO, G.A.; BERGAMASCHI, H.; BERGONCI, J.I.; KRÜGER, C.A.M.B.; COMIRAN, F. \& HECKLER, B.M.M. Retenção e disponibilidade de água às plantas, em solo sob plantio direto e preparo convencional. R. Bras. Eng. Agríc. Amb., 13:855-864, 2009.

DE MARIA, I.C.; CASTRO, O.M. \& SOUZA DIAS, H. Atributos físicos do solo e crescimento radicular de soja em Latossolo Roxo sob diferentes métodos de preparo do solo. R. Bras. Ci. Solo, 23:703-709, 1999.

DE SOUZA, P.I.; EGLI, D.B. \& BRUENING, W.P. Water stress during seed filling and leaf senescense in soybean. Agron. J., 89:807-812, 1997.

DIAS JUNIOR, M.S. Compactação do solo. In: NOVAIS, R.F.; ALVAREZ V., V.H. \& SCHAEFER, C.E.G.R., ed. Tópicos em ciência do solo. Viçosa, MG, Sociedade Brasileira de Ciência do Solo, 2000. v.1. p.55-94.

ELTZ, F.L.F.; PEIXOTO, R.T.G. \& JASTER, F. Efeitos de sistemas de preparo de solo nas propriedades físicas de um Latossolo Bruno álico. R. Bras. Ci. Solo, 13:259-267, 1989.

EMPRESA BRASILEIRA DE PESQUISA AGROPECUÁRIA . EMBRAPA. Centro Nacional de Pesquisa de Solos. Manual de métodos de análise de solo. 2.ed. Brasília, 1997. 212 p.

EMPRESA BRASILEIRA DE PESQUISA AGROPECUÁRIA EMBRAPA. Centro Nacional de Pesquisa de Solos. Sistema brasileiro de classificação do solo. 2.ed. Rio de Janeiro, 2006. 306p.

FERREIRA, D.F. Programa Sisvar.exe: Sistema de análise de variância. Lavras, Universidade Federal de Lavras, 2007.

GIOTTO, E.; ROBAINA, A.D. \& SULZBACH, L. Agricultura de precisão com o Sistema CR Campeiro 5. Santa Maria, Universidade Federal de Santa Maria, 2004. 330p.

LAFLEN, J.M.; AMEMIYA, M. \& HINTZ, E.A. Measuring crop residue cover. J. Soil Water Conserv., 36:341-3, 1981.

LANZANOVA, M.E.; NICOLOSO, R.S.; LOVATO, T.; ELTZ, F.L.F.; AMADO, T.J.C. \& REINERT, D.J. Atributos físicos do solo em sistema de integração lavoura-pecuária sob plantio direto. R. Bras. Ci. Solo, 31:1131-1140, 2007.

LIMA, C.L.R.; PAULETTO, E.A.; GOMES, A.S. \& SILVA, J.B. Estabilidade de agregados de um Planossolo sob diferentes sistemas de manejo. R. Bras. Ci. Solo, 27:199-205, 2003.

LIMA, C.L.R.; REINERT, J.D.; REICHERT, J.M.; SUZUKI, L.E.A.S. \& GUBIANI, P.I. Qualidade físico-hídrica e rendimento de soja (Glycine max L.) e feijão (Phaseolus vulgaris L.) de um Argissolo Vermelho distrófico sob diferentes sistemas de manejo. Ci. Rural, 36:1172-1178, 2006.
MENEGATTI, L.A.A. \& MOLIN, J.P. Remoção de erros em mapas de produtividade via filtragem de dados brutos. $\mathrm{R}$. Bras. Eng. Agríc. Amb., 8:126-134, 2004.

MOLIN, J.P. Definição de unidades de manejo a partir de mapas de produtividade. Eng. Agric., 22:83-92, 2002.

NICOLOSO, R.S.; AMADO, T.J.C.; SCHNEIDER, S.; LANZANOVA, M.E.; GIRARDELLO, V.C. \& BRAGAGNOLO, J. Eficiência da escarificação mecânica e biológica na melhoria dos atributos físicos de um Latossolo muito argiloso e no incremento do rendimento de soja. R. Bras. Ci. Solo, 32:1723-1734, 2008.

NIMER, E. Climatologia do Brasil. 2.ed. Rio de Janeiro, IBGE, Departamento de Recursos Naturais e Estudos Ambientais, 1989. 442p.

PACHECO, E.P. \& CANTALICE, J.R.B. Análise de trilha no estudo dos efeitos de atributos físicos e matéria orgânica sobre a compressibilidade e resistência à penetração de um Argissolo cultivado com cana-de-açucar. R. Bras. Ci. Solo, 35:417-428, 2011.

POTT, C.A. \& DE MARIA, I.C. Comparação de métodos de campo para determinação da velocidade de infiltração básica. R. Bras. Ci. Solo, 27:19-27, 2003.

REICHERT, J.M.; SUZUKI, L.E.A.S.; REINERT, D.J.; HORN, R. \& KANSSON, I.H. Reference bulk density and critical degree-of-compactness for no-till crop production in subtropical highly weathered soils. Soil Tillage Res., 102:242-254, 2009.

ROTH, C.H.; MEYER, B. \& FREDE, H.G. A portable rainfall simulator for studying factors affecting runoff, infiltration and soil loss. Catena, 52:79-85, 1985.

SECCO, D. \& REINERT, D.J. Efeitos imediato e residual de escarificadores em Latossolo Vermelho-Escuro sob plantio direto. Eng. Agric.,16:52-61, 1997.

SECCO, D.; ROS, C.O.; SECCO, J.K. \& FIORIN, J.E. Atributos físicos e produtividade de culturas em um Latossolo Vermelho argiloso sob diferentes sistemas de manejo. R. Bras. Ci. Solo, 29:407-414, 2005.

SILVA, A.P.; KAY, B.D. \& PERFECT, E. Characterization of the least limiting water range. Soil Sci. Soc. Am. J., 58:1775-1781, 1994.

SILVA, A.P.; TORMENA, C.A.; DIAS JUNIOR, M.; IMHOFF, S \& KLEIN, V.A. Indicadores da qualidade física do solo. In: JONG van LIER, Q. Física do solo. Viçosa, MG, Sociedade Brasileira de Ciência do Solo, 2010. 208p.

SILVA, V.R.; REICHERT, J.M.; REINERT, D.J. \& BORTOLUZZI, E.C. Soil water dynamics related to degree of compaction of two Brazilian Oxisols under no-tillage. R. Bras. Ci. Solo, 33:1097-1104, 2009.

SILVA, V.R.; REICHERT, J.M. \& REINERT, D.J. Resistência mecânica do solo à penetração influenciada pelo tráfego de uma colhedora em dois sistemas de manejo do solo. Ci. Rural, 30:795-801, 2000.

SIONIT, N. \& KRAMER, P.J. Effect of water stress during different stages of growth of soybean. Agron. J., 69:274$278,1977$. 
SIQUEIRA, O.J.F. \& DENARDIN, J.E. Equipamento para medir a taxa de infiltração de água no solo utilizando anéis concêntricos em um sistema com nível de água constante. R. Bras. Ci. Solo, 9:73-75, 1985.
TORMENA, C.A.; SILVA, A.P. \& LIBARDI, P.D. Caracterização do intervalo hídrico ótimo de um Latossolo Roxo sob plantio direto. R. Bras. Ci. Solo, 22:573-581, 1998. 